\title{
FILSAFAT KETUHANAN MENURUT PLATO
}

\author{
Ivan Th. J. Weismann
}

\begin{abstract}
Intisari
Plato adalah filsuf pertama yang menulis secara filosofis dan secara sistematik teologis mengenai konsep Ketuhanan sehingga dapatlah dikatakan bahwa ia adalah peletak dasar bagi ilmu teologia dan memberikan pengaruh besar bagi perkembangan filsafat Barat khususnya tentang konsep Ketuhanan. Pemikiran Plato tentang Ketuhanan adalah upayanya untuk mereformasi konsep Ketuhanan yang terdapat pada masyarakat Yunani kuno. Tulisan ini berupaya menganalisa dan memahami Ketuhanan menurut Plato agar pembaca masa kini dapat mengerti lebih dalam lagi tentang konsep Ketuhanan yang dipahami masyarakat Yunani kuno dan khususnya menurut Plato, dan juga dapat dijadikan sebagai bahan perbandingan bagi filsafat Ketuhanan pada masa kini.

Filsafat Ketuhanan menurut Plato ini penulis jelaskan dengan memperhatikan dimensi metafisika, epistemologi, dan etika.
\end{abstract}

\section{Pendahuluan}

Konsep Tuhan dalam filsafat Yunani pada awalanya diambil dari kata deus yang berarti "dewa Zeus", lalu dalam perkembangannya digunakanlah kata theos yang salah satu pengertiannya ialah Tuhan. Walaupun konsep Ketuhanan Plato berasal dari kata deus tetapi Tuhan yang dimaksud Plato bukanlah dewa Zeus (Barimah-Apau, 1989: 7-10).

Kata "theos" dalam bahasa Yunani pada masa Yunani kuno tidak memiliki arti yang sama dengan kata Tuhan menurut pengertian dalam kitab suci umat Kristen. G.M.A. Grube menulis bahwa bagi masyarakat Yunani kuno, Tuhan adalah suatu yang bermakna predikatif. Alkitab mengatakan Tuhan itu kasih atau Tuhan itu baik, menegaskan tentang eksistensi sesuatu yang misterius, atau menjelaskan tentang salah satu sifat Tuhan. Bagi masyarakat Yunani kuno aturannya ialah sebaliknya. Mereka berkata, bahwa Kasih itu Tuhan atau Keindahan itu Tuhan, yang maknanya tidak mengasumsikan eksistensi tentang suatu Ketuhanan yang misterius, tetapi menjelaskan tentang kasih dan keindahan sebagai suatu realitas. Perkataan bahwa kasih atau kemenangan adalah
Tuhan dimaknai sebagai sesuatu yang melebihi dari manusia, sesuatu yang tidak dapat mati dan kekal, suatu kuasa yang bekerja dalam dunia, yang tidak lahir bersama manusia, dan tetap ada walaupun semua manusia telah tiada, itulah yang disebut Tuhan. Oleh karena itu, kata Tuhan bagi masyarakat Yunani kuno juga diterapkan pada matahari, bulan, planet dan benda-benda langit lainnya, tetapi sekalipun disebut Tuhan bukan berarti masyartakat Yunani kuno menjadikan benda-benda itu sebagai objek penyembahan, atau diartikan sebagai Tuhan menurut pemahaman masyarakat moderen, melainkan disebut Tuhan alasannya hanya karena benda-benda langit itu adalah lebih besar dan lebih bertahan hidup lama dari pada hidup manusia (Grube, 1980: 150151).

\section{Dimensi Metafisika atas Ketuhanan Plato Tuhan yang Tidak Dapat Dikenal}

Salah satu karya Plato yang berjudul Cratylus menjelaskan bahwa Tuhan tidak dapat dikenal dan tidak ada esensi-Nya yang dapat dikenali. Nama-nama yang digunakan untuk menunjukkan sifat-sifat 
Tuhan tidak berarti manusia telah sungguhsungguh mengenal-Nya. Nama-nama itu tidak sesungguhnya menjelaskan sifat atau esensi Tuhan, tetapi hanya pendapat yang lemah dari manusia tentang Tuhan. Namanama itu hanya bertujuan sebagai konsep yang dibuat manusia tentang Ketuhanan. Tidak ada nama-nama atau konsep yang universal tentang Ketuhanan. Sekalipun dalam hal ini Plato menentang naturalisme dan antrofomorfisme terhadap Ketuhanan, tetapi Plato tidak mengesampingkan konsep Ketuhanan dalam filsafatnya (Barimah-Apau, 1989: 29-31).

\section{Eksistensi Tuhan}

Plato melihat, baik orang Yunani maupun bukan Yunani percaya akan eksistensi Tuhan, jika tidak maka Tuhan bukanlah suatu konsep universal. Tuhan bukanlah fiksi, melainkan realitas yang paling pasti, dan tidak patut diragukan (Plato, Laws, 887). Tuhan itu ada karena ada penyembahan bagi-Nya menurut budaya setempat. Setiap ma-syarakat memiliki pengetahuan akan Tuhan yang diperoleh dari mitos dan cerita yang diteruskan dari generasi ke generasi (Plato, Laws, 887-888). Inilah bukti yang dikemukan Plato tentang eksistensi Tuhan.

Bukti lain yang dikemukakan Plato tentang eksistensi Tuhah bahwa dengan memandang bumi, matahari, bintang, alam semesta, dan memandang pula pada proses yang ajaib dari pergantian musim dari tahun ke tahun dan dari bulan ke bulan, inilah bukti eksistensi Tuhan (Plato, Laws, 886). Keteraturan dan ketertiban yang terdapat pada benda-benda langit dan musim-musim dimungkinkan terjadi hanya jika ada suatu inteligensi tertinggi di alam semesta ini atau yang disebut pula sebagai jiwa alam semesta. Karya Plato yang berjudul Apology menjelaskan konsep Ketuhanan Plato sebagai intelegensi yang tertinggi di antara seluruh intelegensi yang terdapat di setiap jiwa di seluruh alam semesta dan setiap intelegensi jiwa yang terdapat di seluruh alam semesta itu berasal dan kembali kepada intelegensi tertinggi itu yang disebut sebagai Tuhan atau jiwa alam semesta (Barimah-Apau, 1989: 27).

\section{Ketuhanan Plato sebagai Jiwa Alam Semesta}

Tuhan bagi Plato yang dipahami sebagai jiwa alam semesta maksudnya ialah sebagai sumber terutama dari semua gerakan yang terjadi dalam alam semesta. Tuhan yang menggerakkan matahari dan bintang-bintang, mengatur gerakan semua benda langit berada dalam orbitnya masing-masing. Sebagai prinsip yang menggerakkan, Tuhan disebut "jiwa" bagi benda-benda langit yang secara fisik adalah tubuh bagi Tuhan (Lodge, 1956: 191).

Oleh karena Tuhan disebut sebagai "jiwa alam semesta" maka sifat-sifat Tuhan itu dapat dikenal lebih jauh lagi dari pada sifat-sifat yang dimiliki dalam jiwa manusia. Phaedo adalah salah satu karya Plato yang menjelaskan tentang immortalitas jiwa manusia yang memiliki sifat yang sama dengan sifat Tuhan sebagai "jiwa". Menurut Plato jiwa manusia secara "dialektik" akan naik mencapai "intelegensi tertinggi" (jiwa alam semesta) sebagai yang memberikan sifat Ketuhanan kepada jiwa manusia. Dialektika menurut Plato dalam karyanya Republik, VII, 533534 , adalah proses argumen rasional, kritikan atas asumsi-asumsi, dan mengeliminasi hipotesis-hipotesis hingga mencapai prinsip pertama yang merupakan dasar yang tak tergoyahkan. Dialektika juga adalah prosedur yang berupaya untuk mencapai puncak pengetahuan dan mencapai pengertian akan Kebaikan atau mencapai pengetahuan akan yang Absolut.

Sifat-sifat Ketuhanan yang melekat pada jiwa manusia adalah alasan jiwa tersebut disebut sebagai immortal, jiwa yang demikian itulah yang membuat 
manusia dapat mengenal sifat-sifat Tuhan. Sifat-sifat jiwa yang sama dengan sifat-sifat Tuhan ialah simpel, tidak dapat binasa, tidak dapat dimusnahkan, tidak dapat berubah, memberi kehidupan bagi tubuh, kekal dan senantiasa sejalan dengan Keindahan Absolut (Barimah-Apau, 1989: 41-42).

Tuhan sebagai Demiurge

Ketuhanan Plato dipandang sebagai suatu pekerjaan aktif individu, itu sebabnya Tuhan menurut Plato disebut sebagai "Demiurge" yang secara etimologis berarti "dia milik umat" (demios) dan "bekerja" (ergon). Demiurge dipandang sebagai pencipta. Tetapi R. G. Collingwood lebih suka menyebut Tuhannya Plato bukan pencipta tetapi yang membuat atau menjadikan sesuatu berdasarkan model yang sudah ada sebelumnya, yang disebut sebagai model pra-eksisten (Collingwood, 1962: general readings). Kata "membuat" didefinisikan sebagai "membawa sesuatu dalam eksistensinya dari berbagai kombinasi atau dari sesuatu yang lain", sedangkan "mencipta" adalah "melahirkan dari unsur-unsur non pra-eksisten atau dari tidak ada". Richard D. Mohr menjelaskan bahwa Demiurge menurut Plato sebagai "pencipta" bukan dalam arti Mahakuasa seperti Tuhan dalam Kekristenan. Demiurge tidak menciptakan materialnya, dia menemukan materi-meteri tersebut, lalu kemudian membuat dunia yang materi atau modelnya sudah ada ini menjadi serupa mungkin dengan model Ideal (model pra-eksisten). Demiurge seperti seniman, pencipta keindahan, hanya membuat dunia ini menjadi indah atau membuatnya nampak lebih baik. Demiurge sebagai "pencipta" harus diartikan hanya sebagai "sumber" stabilitas dan permanensi, "sumber" ketertiban dan keteraturan, namun makna "sumber" di sini bukan sebagai penyebab, atau segala sesuatu berasal dari dirinya sendiri, atau yang bertanggung jawab atas semua ketertiban dan keteraturan, tetapi hanya sebagai yang mengupayakan, memfungsikan dan menyatakan ketertiban dan keteraturan itu sebagai bagian dari pekerjaannya (Mohr, 1985: 132, 134, 141).

Tuhan sebagai pencipta dalam filsafat Plato tidak harus diartikan secara literal, tetapi sebagai simbolisasi sumber dan asal mula semua kehidupan, sekarang dan selamanya. Jika Tuhan menurut Plato bukan Pencipta, siapakah Pencipta Yang Mahakuasa itu? Inilah persoalan yang masih misterius dalam filsafat Plato.

\section{Tuhan Hanya sebagai Ide}

\section{Bukan sebagai suatu Pribadi}

Tidak ada tradisi dalam budaya Yunani kuno, sebagaimana dalam pemikiran Kekristenan yang menganggap konsep kepribadian sebagai atribut esensial bagi Ketuhanan. G.C.Field berkata," Tuhan dalam pengertian sebagai jiwa alam semesta menurut Plato bukanlah sesuatu yang berpribadi. Dia tidak dipikirkan sebagai suatu kepribadian individual seperti individu lainnya" (Field, 1969: 108).

Ketuhanan Plato adalah impersonal oleh karena bagi Plato Tuhan itu adalah Ide. Bagi Plato, Ide berarti suatu kualitas atau esensi yang kekal dan tidak berubah; yang eksis terpisah dari dunia fisik; dan juga eksistensinya terpisah dari pikiran yang hendak mencapai atau mengetahuiNya. Ide bukan saja representasi dari segala sesuatu, tetapi Ide adalah segala sesuatu. Ide adalah yang memberi kehidupan, entitas spiritual (Glenn, 1963: 74). Akan tetapi kata Ide berasal dari kata eidos yang menurut kamus berarti suatu paham dalam pikiran. Selain itu, "ide" juga secara filosofis diartikan sebagai representasi universal yang ada dalam pikiran manusia sebagai akibat dari Ide yang sesungguhnya. Tuhan sebagai Ide dalam pengertian kamus dan filosofis ini berarti Yang Ada hanya dalam pikiran. Itu sebabnya Ketuhanan Plato ialah Kebaikan, Keindahan, Kesatuan dan seterusnya, dengan kata lain berupa 
konsepsi-konsepsi saja. C. Ritter berkata bahwa Ide Plato tidak lebih dari menunjuk pada dasar objektif suatu konsepsi; dasar objektif ini hanya memberikan keabsahan dan kepastian bagi konsepsi (Ritter, 1933: 75). Jika kemudian, Tuhan menurut Plato itu disebut sebagai Pencipta atau Bapa, atau disebut sebagai Eros atau Kasih, bukan berarti Tuhan menurut Plato itu mampu memelihara dan mengasihi manusia seperti sesuatu yang berpribadi, melainkan diartikan sebagai sesuatu yang hanya mampu menolong, mengarahkan manusia menuju kebaikan sesuai dengan dirinya yang adalah Ide dari segala ide.

\section{Tuhan sebagai Yang Satu dan Plural}

Plato percaya bahwa Ide Tuhan atau Kebaikan adalah Satu Yang Kekal. Akan tetapi, Plato juga percaya pada suatu makhluk supernatural yang adalah semua di dalam semua. Cicero menulis bahwa ada banyak pembicaraan Plato yang tidak konsekuen. Plato percaya bahwa dunia adalah Tuhan, begitu pula dengan langit, bintang, bumi, jiwa dan semua Ketuhanan yang dikenal oleh para leluhur. Pada saat yang sama Plato juga berusaha memperkenalkan figur Tuhan. Plato menyatakan bahwa Tuhan adalah Satu dan Unik, tetapi kemudian menjelaskan pula sebagai pluralitas dengan adanya beberapa Tuhan (dewa) (Barimah-Apau, 1989: 265). Cicero rupanya kurang mengenal konsep Plato mengenai Ketuhanan, bahwa secara hirarki yang tertinggi ialah Tuhan Yang Satu itu dan di bawah-Nya ada pula dewa-dewa lain yang berperan dalam alam yang disebut pula sebagai "Tuhan".

Singkatnya, konsep Plato mengenai Yang Satu ialah dalam arti sebagai Sumber; sebagai Yang Tertinggi; dan sebagai Yang Pertama dari segala ide, dari segala kebaikan dan dari segala hikmat, itulah Tuhan Yang Satu, tetapi tidak sebagai Pencipta seperti pada Tuhan dalam Alkitab. Sedangkan pluralitas dalam Ketuhanan Plato ialah menunjuk pada tingkat-tingkat dalam Ketuhanan melalui proses transformasi atau "emanasi" bahwa dari Yang Satu keluarlah yang banyak dan dari yang banyak itu Yang Satu itu terbit dan menjadi nyata. Ketuhanan Plato sebagai Yang Satu dan Plural tidak sama pengertiannya dengan Ketuhanan Yang Maha Esa ataupun dengan Allah Tritunggal dalam Kekristenan.

\section{Dimensi Epistemologi \\ Atas Ketuhanan Plato}

Plato memahami Tuhan sebagai Kebaikan dalam realitas (Plato, Republic, II, 379). Tujuan tertinggi kehidupan manusia ialah kecintaan untuk memiliki secara kekal Kebaikan itu (Barimah-Apau, 1989: 91). Kebaikan bukan esensi, tetapi jauh melampaui esensi Ketuhanan dan kekuasaan. Kebaikan bukan saja sumber kemampuan inteligen dalam semua objek pengetahuan, tetapi juga adalah esensi dan keberadaannya (Plato, Republic, VI, 509). Kebaikan adalah kondisi "kebenaran". Kebaikan adalah prinsip segala sesuatu, baik yang ada maupun yang tidak ada. Kebaikan transenden atas segala sesuatu, oleh karena itu adalah penyebab dan asal mula segala sesuatu (Barimah-Apau, 1989: 75).

Tuhan sebagai Kebaikan adalah tempat kesempurnaan keberkatan yang tertinggi. Suatu negara akan mengalami keberkatan tersebut bergantung pada para penguasanya memiliki sifat Kebaikan itu dalam diri mereka. Menurut Plato hanya para filsuf yang memiliki sifat Kebaikan itu. Plato berkata bahwa, masyarakat tidak pernah berkembang dan persolan tidak akan pernah terselesaikan hingga para filsuf menjadi raja atau hingga mereka yang disebut para raja dan para penguasa benarbenar menjadi para filsuf, dan kekuasaan politik dan filsafat berada di tangan yang sama (Plato, Republic, V, 473).

Siapakah para filsuf itu menurut Plato? Mereka yang hatinya ditetapkan pada yang benar bukan pada pendapat 
umum (Plato, Republic, V, 480). Filsuf memiliki kapasitas untuk mencapai yang kekal (Plato, Republic, VI, 484). Filsuf cinta akan kebenaran bukan pada dunia inderawi yang selalu berubah-ubah atau pendapat umum yang sifatnya sementara, tetapi pada realitas yang tidak berubah yaitu objek pengetahuan (episteme) (Barimah-Apau, 1989: 58).

Seseorang disebut filsuf juga harus memiliki empat kualitas atau kebajikan yang terutama, yaitu hikmat (sophia), semangat (andreia), disiplin atau pengendalian diri (sophrosune), dan keadilan (dikaiosune atau osiotes) (BarimahApau, 1989: 61). Sifat-sifat ini harus dimiliki untuk memerintah atau menjadi penguasa.

Filsuf seharusnya pula dapat mencapai konsep yang lebih tinggi dari pada empat kualitas atau kebajikan yang terutama itu. Konsep itu ialah nilai atau Kebaikan yang tertinggi. Kualitas "Kebaikan" itu bukan sesuatu yang dapat dilihat dan dipahami dengan mata inderawi, namun dapat dikenali hanya oleh mata pikiran. Hal-hal yang partikular yang dapat dilihat dengan mata, tetapi hanya hal-hal yang universal yang dapat dilihat dengan "mata" pikiran. Ide Kebaikan itulah hal yang universal.

Hubungan antara hal-hal yang partikular dengan universal, dan hubungan antara yang dipahami secara inderawi dengan yang dipahami secara intelektual, Plato menjelaskannya dengan membagi dunia pengetahuan atas dua bagian. Bagian terbesar ialah dunia yang dicapai oleh intelek (noeton) atau dunia ilmu pengetahuan (episteme) dan bagian yang terkecil adalah dunia yang dipahami oleh indera (horaton) atau dunia opini atau pendapat umum (doxa). Dunia intelek (bagian terbesar) terbagi atas dua sikap yaitu sikap pertama ialah intelegensi (noesis) yaitu sikap yang penuh pengertian, puncak visi kebenaran tertinggi yang dicapai dengan metode "dialektika". Sikap yang kedua dari dunia intelek ialah akal budi (dianoia) yaitu prosedural matematik yang asumsi-asumsinya tidak dapat terbantahkan. Dunia inderawi (bagian terkecil) juga terbagi atas dua sikap yaitu sikap pertama ialah keyakinan (pistis) yaitu kepercayaan pada hal-hal moral dan fisik yang berhubungan dalam menuntun perilaku kehidupan, tetapi tidak sepenuhnya dipikirkan atau dipertimbangkan dalam pikiran. Yang kedua ialah ilusi (eikasia) yaitu berbagai ilusi yang memenuhi banyak pikiran orang awam (BarimahApau, 1989: 66-68).

Sikap intelegensi (noesis) adalah level tertinggi untuk mencapai realitas Kebaikan tertinggi yang dicapai bukan dengan mata inderawi, tetapi dengan mata pikiran. Level tertinggi ini adalah rasionalitas dunia pengetahuan yang fundamental yang memampukan setiap orang untuk menaati hukum, apakah hukum itu rasional, alami atau manusiawi (Barimah-Apau, 1989: 68). Jiwa yang level pengetahuannya hanya sampai pada ilusi tidak dapat mengenal dan mencintai Kebaikan, melainkan hanya hal-hal inderawi. Dia tidak dapat membedakan antara realitas dan ilusi. Hanya filsuf yang dapat sampai pada pengenalan dan melihat Kebaikan. Hal itu adalah sesuatu yang ilahi dan tidak semua mata dapat memandangnya (BarimahApau, 1989: 76). Inilah ketentuan-ketentuan agar setiap orang dapat mengenal dan mencapai Kebaikan Tertinggi yang adalah Tuhan, yaitu memiliki kualitas filsuf atau dengan menjadi filsuf, dengan begitu dia pun layak untuk menjadi raja atau penguasa atau memerintah suatu negara.

\section{Dimensi Etika Atas Ketuhanan Plato}

Ketuhanan Plato mendapat sambutan dalam doktrin politik Yunani. W. Durant berkata bahwa Plato percaya bahwa suatu bangsa tidak dapat menjadi kuat jika tidak percaya pada Tuhan (Durant, 1952: 24). Bagi Plato pengorbanan, pujian, berbagai upacara tidak dapat 
membawa harapan bagi bangsa, kecuali Tuhan yang dapat menuntun, mengarahkan dan melindungi bangsa itu karena hukum dan aturan-Nya tidak berubah, penuh kemurnian dan keadilan. Menurut Plato, suatù negara seharusnya memfungsikan anggota-anggotanya untuk taat kepada hukum, ketaatan itu bukan didasarkan pada kepentingan kelompok, tetapi pada Tuhan yang perintah-perintahNya dikenal dalam hukum itu. Prinsip fundamental pemerintahan yang baik ialah bahwa kedaulatan bukan pada suatu pribadi atau suatu kelompok, tetapi kepada hukum yang impersonal (Plato, Law, 713).

Plato mengatakan pula bahwa segala sesuatu berada dalam rencana Tuhan, dan semua kehidupan manusia berada dalam pemerintahan dan pengendalian Tuhan, prinsip ini disebut "siklus alam". Mereka yang keluar dari rencana Tuhan dan tidak taat, mereka keluar dari siklus alam itu dan layak mendapat hukuman ilahi. Oleh karena itu manusia yang ingin hidup bahagia harus dengan lemah lembut dan kerendahan hati menjadi serupa dengan Tuhan yang adalah ukuran segala sesuatu, yaitu dengan cara menuruti ukuran yang benar, hukum (Plato, Law, 716).

Hal yang paling indah dan paling benar bagi orang benar perbuat ialah memberikan persembahan, pengorbanan dan doa kepada Tuhan agar mencapai kebahagiaan dalam kehidupan ini. Tetapi doa orang yang tidak benar akan sia-sia karena Tuhan tidak mau mendengar mereka (Plato, Law, 716). Ini berarti bahwa rencana Tuhan tidak dapat diubahkan oleh doa atau persembahan atau upacara magis dari para pelaku kejahatan. Seorang berdosa tidak layak di hadapan Tuhan sebelum disucikan (Barimah-Apau, 1989: 215). Moralitas adalah pendorong bagi setiap orang untuk berbuat baik. Tuhan menjadi pengendali dorongan berbuat baik itu. Ketaatan kepada Tuhan adalah norma perilaku tertinggi yang seharusnya menjadi aspirasi setiap manusia (Barimah-Apau, 1989: 27).

Dimensi etika atas Ketuhanan Plato ditemukan pula dalam karya Plato yang berjudul Theaetetus. Tuhan dalam karyanya ini bukanlah penyebab kejahatan melainkan hanya penyebab kebaikan, sekalipun kejahatan berarti kekurangan Ketuhanan, kejahatan tidak mendapat tempat dalam dunia Ketuhanan, selain berada di dalam dunia saja. Menjadi orang benar atau untuk berbuat baik harus selalu dalam lingkup Ketuhanan. Kehidupan moral manusia selalu berhubungan erat dengan eksistensi Tuhan. Seluruh kehidupan moral manusia dipahami dalam menuruti teladan Tuhan sebagai ukuran yang sedapat mungkin harus dicapai manusia. Oleh karena itulah yang menjadi prinsip dan tujuan hidup manusia. Jiwa yang berasal dari natur ilahi, tidak dapat menjadi lain selain menjadi seperti Tuhan. Kesempurnaan ideal terealisasi dalam kesempurnaan Tuhan yang absolut (Barimah-Apau, 1989: 46).

Dimensi etika atas Ketuhanan Plato memberikan pengajaran untuk menghormati sesama manusia khususnya kepada orang tua. Adapun pribadi-pribadi yang layak dihormati manusia dijelaskan Plato secara hirarkhi (Plato, Law, 717-718):

1. Tuhan Olimpus

2. Dewa-dewa yang mengendalikan pemerintahan.

3. Dewa-dewa leluhur yang berada di dunia bawah.

4. Roh-roh (spiritisme/ daimon)

5. Para pahlawan yang telah gugur.

6. Orang tua yang masih hidup.

7. Merawat kuburan orang tua yang sudah meninggal.

Secara ringkas, etika Plato dipikirkan sebagai pengetahuan tentang kehidupan ilahi atau kehidupan yang baik dan bagaimana mencapainya. James Duerlinger secara ringkas menjelaskan bahwa kehidupan ilahi itu dicapai bergantung pada hikmat praktis atau 
pelatihan moral, yaitu pengetahuan tentang kualitas atau kebajikan moral; dan juga bergantung pada hikmat teoretis atau disebut pengetahuan kontemplasi dengan bagian utamanya ialah teologi yang dikembangkan dengan metode dialektika atau logika dan kasih kepada Tuhan (Duerlinger: 312).

\section{Kesimpulan}

Agama Plato bukan agama "spiritual" dengan Ketuhanan adalah Logos-Allah yang berinkarnasi, melainkan agama Plato adalah agama "intelektual" dengan Ketuhanan yang impersonal (tidak berpribadi) yang disebut sebagai "Jiwa alam semesta" dalam arti sebagai sumber gerakan dan keteraturan dalam alam semesta, sehingga alam semesta bisa mandiri dan mengorganisasikan dirinya. Oleh karena itu, Ketuhanan Plato bukanlah pencipta yang eksternal yang supernatural dan penciptaan menurut Plato bukanlah dari ketiadaan mutlak atau ex nihilio, melainkan dalam kerangka emanasi dan partisipasi dari apa yang disebut sebagai Ide dari segala ide atau Intelegensi tertinggi di alam semesta yang berupa hukumhukum yang memberikan ketertiban dan keteraturan dalam segala makhluk dan benda dalam alam semesta ini. Itu sebabnya benda-benda langit dalam konsep Ketuhanan Plato disebut pula Tuhan karena di dalamnya mengandung "jiwa alam semesta", namun benda-benda langit itu sekalipun disebut Tuhan tidak dijadikan sebagai objek penyembahan.

Ketuhanan Plato yang disebut pula sebagai Demiurge dalam arti bahwa Tuhan semacam ini bukan menjadi seluruh penyebab suatu peristiwa. Tuhan adalah pengaruh kreatif pada setiap peristiwa, tetapi tidak menjadi satu-satunya pencipta peristiwa itu karena tiap-tiap peristiwa aktual dipengaruhi oleh pengaruh kreatif peristiwa-peristiwa sebelumnya dan juga memiliki kekuatan untuk menciptakan dirinya sendiri. Tuhan dalam "mencipta" atau mengatur semua peristiwa tidak menyela proses-proses alam di sana-sini. Tuhan tidak memaksa, melainkan mengajak. Tuhan tidak menciptakan secara sepihak, melainkan sebagai Ide dari segala ide dan sebagai Intelegensi tertinggi memberikan inspirasi kepada para makhluk agar mereka menciptakan diri mereka sendiri dengan menanamkan suatu perasaan penting yang terus berkembang secara bertahap dalam diri mereka. Melalui ajakan ilahi yang terus-menerus inilah (melalui proses dialektika) keteraturan muncul dari ketidakteraturan, dan dari sini muncullah bentuk-bentuk eksistensi yang lebih tinggi, yang menampilkan bentukbentuk nilai yang lebih tinggi dan yang memampukan manusia untuk mencapai Kebaikan tertinggi yang disebut sebagai Tuhan.

Menurut Ketuhanan Plato, Tuhan bukan penyebab kejahatan sejak Dia hanyalah penyebab kebaikan dan yang baik secara sempurna. Kejahatan bukan sebagai kekuatan yang aktif dan pokok, melainkan hanya sebagai kekurangan dari yang baik, memberikan landasan agar kebaikan bisa menyerang dan mengalahkannya. Manusia untuk menjadi benar dan berbuat baik harus memiliki keterpautan yang sangat erat dengan keberadaan Tuhan. Seluruh kehidupan moral manusia harus dalam keserupaan dengan Tuhan dalam segala kemugkinan upayanya. Oleh karena itu, Tuhan adalah pedoman dan tujuan kehidupan. Jiwa yang memiliki sifat ilahi tidak memiliki ruang lingkup lain, kecuali menjadi serupa dengan Tuhan. Kesempurnaan yang ideal hanya dalam kesempurnaan Tuhan yang mutlak. Cara ini pula adalah jalan bagi jiwa setelah kematian fisik kembali kepada asal mulanya, yaitu tinggal dalam keberadaan Tuhan. 


\section{Kepustakaan}

Barimah-Apau, Michael, 1989, The God of Plato in Dialogues, Pontificia Universitas Urbania, Roma.

Collingwood, R. G., 1962, An Essay on Metaphysics, Clarendon Press, Oxford.

Duerlinger, James, Ethics and the Divine Life in Plato's Philosophy, dalam The Journal of Religious Ethics.

Durant, W., 1952, The Story of Philosophy, Simon \& Schuster, New York.

Field, G. C., 1969, The Philosophy of Plato, Oxford University Press, Oxford.
Glenn, P.J., 1963, The History of Philosophy, Herder, London.

Grube, G. M. A., 1980, Plato's Thought, Hackett Publishing Company

Mohr, Richard D., Plato's Theology Reconsider: What the Demiurge Does, dalam History of Philosophy Quarterly, Volume 2, Number 2, April 1985.

Plato, 1952, The Dialogues of Plato, terjemahan: Benjamin Jowett, William Benton, Chicago.

Ritter, C., 1933, The Essence of Plato's Philosophy, Dial Press, New York. 